\title{
Antonio Porchia: la brevedad del extranjero
}

\author{
Fabio Morábito
}

El artículo intenta releer la obra de Porchia a la luz de su condición de inmigrante y de su relación problemática con el idioma castellano, idioma que aprendió tarde, a los 16 años de edad, cuando emigró a Argentina.

Palabras Clave: aforismos, lengua materna, lengua aprendida, estilo, brevedad.

This article "Antonio Porchia: The Brevity of the Foreign" tries to reread Porchia's work in the light of his immigrant status and his problematic relation with Spanish language, a language he learned late, at 16 years old, when he emigrated to Argentina. 

Fabio Morábito

Instituto de Investigaciones Filológicas, UNAM

\section{Antonio Porchia: la brevedad del extranjero}

Al hablar sobre Antonio Porchia se debería partir de una primera comprobación elemental, la de que Porchia sólo escribió aforismos y nunca quiso o nunca pudo ir más allá de esas breves sentencias que germinaban lentamente en él y que, con igual lentitud, tras un arduo trabajo de corrección, encontraban su forma definitiva. Su entrega exclusiva a un género que los escritores modernos suelen cultivar con "la mano izquierda", como un subproducto de su obra "mayor", lo define como un escritor casi arcaico. Es inexacto incluso atribuirle el título de escritor, pues quien escribe aforismos en realidad no los escribe, únicamente plasma por escrito, que es diferente de escribir, breves fragmentos de reflexión que se hallan más próximos a lo oral que a lo escrito. Los aforismos, los proverbios, los dichos, las máximas, las sentencias, guardan en común este carácter espurio, y nos remiten, más que a la idea de texto (de tejido, según la conocida etimología), a la de soplo, de exhalación, o sea a un tipo de verdad más cercana a la boca que a las manos. Porchia, sin embargo, trabajó sus aforismos con las manos, como una urdimbre textual o, para decirlo rápidamente, como poemas. El obsesivo trabajo de corrección al que sometió sus "voces", del que estamos al tanto gracias a los análisis y 
cotejos realizados por Laura Cerrato, ${ }^{1}$ sólo puede entenderse a la sombra de la urdimbre textual con la que están concebidas. Ese hombre que empezó a escribir casi viejo, cuando su única ocupación era cuidar las flores de su jardín; que era frugal para vestir, comer y hablar, debió de rumiar sus sentencias en sus muchas horas de soledad, mientras cuidaba sus plantas. Es probable que, podando aquí y allá, cuidaba también su libro, suprimiendo comas y adjetivos inútiles. Escueta y portátil, su obra lo acompañaba todo el tiempo y, en este sentido, fue el más escritor de todos, entregado sin descanso a su único libro en continuo crecimiento. Tenía fama de escribir muy poco, cuatro o cinco aforismos al año que luego trabajaba arduamente, ${ }^{2}$ pero basta hacer el recuento de sus "voces", que son más de mil entre las que publicó y las que prefirió no publicar, para comprobar que tal parquedad es falsa. ${ }^{3}$ Recluido en su modesta casa, ahorrativo y solitario, rodeado de pocos libros y sin más distracciones que las visitas que le hacían unos cuantos amigos y admiradores, Porchia debía de escribir mucho, pues no necesitaba sentarse a una mesa para hacerlo y podía trabajar cada aforismo de memoria. Apuntaba sus frases en pequeñas hojas de papel, que luego corregía y volvía a corregir, obedeciendo a un afán de perfeccionismo que probablemente se debía al hecho de que, habiendo nacido en Italia, aprendió español hasta los 16 años, edad a la que llegó a Argentina con su familia. Según afirma Boido, "no llegó nunca a reconocer totalmente como propio" el idioma aprendido. Por eso, no es aventurado sostener que la exclusividad con que se entregó al género más breve de todos se debe en parte a su inseguridad lingüística. En el terreno acotado del aforismo Porchia podía

${ }^{1}$ En especial en su "Prefacio" a Voces abandonadas.

${ }^{2}$ Así opinaba uno de sus amigos, el escultor Líbero Badii. Ver Dujovne Ortiz, "Antonio Porchia".

${ }^{3}$ Utilizo la edición de Voces reunidas de Daniel González Dueñas y Alejandro Toledo. 
controlar obsesivamente cada elemento de la frase, cosa que no habría sido posible en ningún otro género. La ausencia, en el aforismo, de una verdadera dimensión compositiva, de una tridimensionalidad que abre el texto hacia una multitud de direcciones, fue con toda probabilidad la razón por la que Porchia hizo de él su religión única. No olvidemos, por otra parte, que se sentía más próximo a la pintura que a la literatura. Casi todos sus amigos eran pintores y fue la pintura, probablemente, más que la poesía, la que le proveyó de un modelo para sus "voces", porque Porchia escribe como si "diera cabida" a cada palabra, como si cada palabra se hubiera ganado arduamente su lugar en la frase, venciendo la resistencia de las otras en una suerte de dolorosa dilatación del poco espacio disponible. A la manera de la salida de un corcho del cuello de una botella, las "voces" crean la sensación de un vacío antes y después de su despliegue en la página, y de ahí ese efecto de condensación y de deletreo atento que produce su lectura.

Es interesante, en este sentido, la cercanía estilística que existe entre él y Alejandra Pizarnik. Es bien conocida la veneración que esta última profesaba por Porchia. También Pizarnik se sentía lingüísticamente insegura. Edgardo Dobry nos recuerda al respecto que uno de los elementos más evidentes de la poesía de Pizarnik "es precisamente esa contención, esa condensación de estilo, de la que acaso no es ajena su incertidumbre acerca del manejo pleno de la lengua, de su plena posesión. Es una hipótesis a tener en cuenta en una poeta que pasó su infancia en una casa en la que apenas se escuchaba el castellano - sus padres, que llegaron a Argentina dos años antes de su nacimiento, hablaban yiddish entre ellos" (Dobry, "En el espejo de Alejandra Pizarnik", 162). Al describir el estilo de Pizarnik, Dobry alude a su concentración "siempre anclada en unos pocos conceptos, en un catálogo de imágenes muy limitado y unas operaciones retóricas básicas, que tienden a repetir, a explicar sin expandir", palabras que son perfectamente 
aplicables a Porchia. Como en Pizarnik, en Porchia hallamos una condensación que, echando mano de la repetición, tiende a deletrear la lengua con un gesto en el que la escritura parece desempeñar un papel de corrector del habla, o de clarificador de la misma. Veamos una "voz" como ésta: "Creo que son los males del alma, el alma. Porque el alma que se cura de sus males, muere". En una versión anterior había escrito: "Y si el alma se curara de sus males, se moriría", que es todavía un aforismo típico, casi una frase de tango. En la versión definitiva, Porchia introduce una dislocación sintáctica que obliga a repetir tres veces la palabra "alma" y, con ello, la exhalación se condensa en texto. A través de esa coma que introduce una pausa perentoria: "del alma, el alma", Porchia nos obliga a leer su frase y a no registrarla meramente como el vehículo de una idea. Si hubiera pues que hallar un "método" en su escritura, éste parece consistir en quitarle a sus "voces" ese carácter de frase subrayada que tienen los aforismos y devolverlas a su condición de texto en minúsculas. ¿Cómo? Acentuando su naturaleza textual, o sea, su carácter imprevisible; para ello, en primer lugar, Porchia modula la voz y convierte cada aforismo en un murmullo, profiriendo sus frases no como quien articula una verdad, sino como quien la recoge o como quien dice una verdad que afloró involuntariamente a sus labios y que debió callarse. "Hablo pensando que no debiera hablar: así hablo".

Esta restitución de algo particular a su trama de origen no es sólo un gesto estilístico, sino metafísico. En todos sus aforismos, Porchia devuelve lo particular a lo general, o sitúa lo particular en su contexto, como se ve claramente desde la primera "voz" de su libro: "Situado en alguna nebulosa lejana hago lo que hago, para que el universal equilibrio de que soy parte no pierda el equilibrio". Apenas cuatro aforismos después, aludiendo a su vida personal, Porchia circunscribe su propia nebulosa con estas palabras: "Mi padre, al irse, regaló medio siglo a mi niñez", en la que traza de un golpe su autobiografía. Sustituto 
del padre, jefe de familia precoz a la muerte de aquél, primogénito encargado de velar por la madre y los hermanos, niño convertido en adulto de la noche a la mañana, Porchia aprendió muy pronto a asumir un papel. Su voz, si alguna voz había cuajado en el adolescente de 16 años que acababa de dejar su tierra natal, tuvo que abdicar ante las exigencias de la nueva realidad que, como hombre mayor de una familia de inmigrantes, lo colocó en una situación de doble orfandad: con respecto al padre recién muerto, pero también a la lengua materna recién abandonada. Porchia se volvió otro, y si algo debió de quedarle claro en ese trance de su vida fue la inconsistencia de todo atributo personal y la capacidad que tiene un individuo de reinventarse. La segunda "voz" de su libro parece aludir a esta mutación radical: "Quien ha visto vaciarse todo, casi sabe de qué se llena todo". Porchia se vacía a tal grado, que para él el verdadero comienzo de su vida será siempre el momento dramático de la llegada al nuevo país. El hecho de que siempre se mostró renuente a hablar de su infancia calabresa parece confirmar su voluntad de adjudicarse un nuevo destino, es más, un nuevo rostro, como sugieren estas palabras de Alicia Dujovne Ortiz: "De su rostro juvenil con cierta falsa hermosura de cantante de ópera va naciendo su rostro definitivo, esa cara para la que él trabajó desde adentro con tremendo fervor" (Dujovne Ortiz, "Antonio Porchia"). Una cara nueva, inédita, que quizá sólo era su cara más antigua, que ahora, lejos de su tierra natal y libre del yugo paterno, puede rescatar con entera libertad.

"Antes de recorrer mi camino yo era mi camino", reza la tercera "voz" de Porchia. Es su primera gran frase: sucinta, apretada, enigmática, quizá el modelo de todo lo que vendrá después. Con ella parece decirnos que nos ponemos en camino sólo para descubrir que no hacía falta movernos; sin embargo, si no nos movemos, no hay forma de descubrirlo. En boca de un emigrante, de alguien que se movió radicalmente y a pesar suyo, la frase parece aludir a una pérdida irreversible. Ser el propio camino es no tener 
necesidad de camino; significa obedecer a la propia hondura, y la hondura no necesita rostro, ni camino, ni emigrar. Hay una "voz" que ilustra esto: "De todos modos he llegado a hoy. Y así llegaré a mi fin. De todos modos". Es una frase que suscribiría cualquier río. De todas las maneras posibles, y a pesar de todo, un río se hace; pero, en un sentido, ya estaba, porque un río revela el río potencial que, oculto en los accidentes del terreno, clamaba por agua; la tierra está llena de ríos que esperan su oportunidad, sólo que ni ellos mismos lo saben hasta que el agua no los confirma en su ser de río; son su camino antes de recorrer su camino. Así, cuando Porchia dice en otro momento: "Un poco de ingenuidad nunca se aparta de mí. Y es ella la que me protege", establece una equivalencia entre la ingenuidad y la hondura. Y, ¿de qué lo protege la ingenuidad? De lo que es superficial: el propio yo, el propio rostro y el propio carácter, o sea, todo aquello para lo cual trabajamos "con tremendo fervor" para hacernos de un lugar en medio de los demás. Porchia pudo haber escrito simple y llanamente: "No dejo nunca de ser del todo ingenuo", pero eligió una formulación más desapegada: "Un poco de ingenuidad nunca se aparta de mî", que sustantiva el atributo de ser ingenuo y lo separa del sujeto, convirtiéndolo de una cualidad psicológica en un vínculo con el mundo. En este breve viraje verbal se percibe su temple existencialista, que suprime la psicología y el yo en favor de la hondura y el camino, y se encuentra también toda su poesía, que persigue un tipo de formulación en la cual cada trozo de la frase luzca limpiamente autónomo y se aclaren todos los nexos implícitos, "barriendo" lo escrito con una luz pareja que devuelva a cada partícula su peso específico y refleje de modo más adherente la sustancial desnudez del individuo. ${ }^{4}$

Así, ese hombre que se vio obligado a asumir un papel de padre de familia a una edad temprana, se curó a una edad tem-

\footnotetext{
${ }^{4}$ Con este mismo espíritu de escansión, podríamos decir de supresión de grumos, leía Porchia sus "voces", como puede comprobarlo cualquiera que escuche el disco compacto que acompaña la edición de Pre-Textos de las Voces reunidas.
} 
prana de la ilusión de ser alguien. "No hallé como quien ser, en ninguno. Y me quedé, así: como ninguno". Fue su secreto triunfo: ser como ninguno, y el rostro que se labró arduamente, tan arduamente como su único libro, fue el rostro de nadie, de un yo cualquiera. ¡Con cuánta ironía trata su propio yo!: "Sí, he hecho algunas cosas que cuando puedo no decírmelas no me las digo, para no ofenderme. Porque yo no quisiera ofender a nadie". Fue otra de sus pasiones: no ofender a nadie, ni a él mismo, y si no le cuesta ninguna dificultad incluirse a sí mismo en ese nadie genérico, es porque se siente como nadie, como ninguno. Por eso, puede decir: "El verdadero 'está bien' me lo digo en el suelo, caído". Parece que Porchia quiere siempre regresar a un punto inicial donde todo está por hacerse y donde, por lo mismo, se tiene la tentación de no hacer nada, porque se sospecha que todo está hecho, ya que uno es su propio camino antes de recorrerlo. Se equivocan, sin embargo, aquellos que han creído ver en él un enamorado del no ser, del vacío y del silencio. Todo lo contrario. Le habría parecido un acto de presunción ser así, y lo afirma claramente: "Sí, trataré de ser. Porque creo que es orgullo no ser". En el talante meridional de ese hombre privó más bien la locuacidad, aunque una locuacidad contenida. Era amante de callarse, pero no del silencio; era frugal en el uso de las palabras, pero comunicativo; y sus "voces", aunque no hagan referencia a su época ni aludan a ningún lugar específico, no son máximas lapidarias escritas desde un sitial equidistante de todo y de todos, sino fragmentos de una conversación íntima y a menudo doliente, inscrita en un aquí y ahora que no es menos real por el hecho de que se hayan borrado sus señas de identidad. En un extenso ensayo sobre Porchia que permanece inédito, ${ }^{5}$ Enrique Foffani ha subrayado justamente el carácter eminentemente dialógico de las Voces. "Muchísimos aforismos se constituyen a partir de la pregunta del otro

\footnotetext{
5 "Las Voces de Porchia entre lo breve y lo fragmentario".
} 
nunca escuchada pero sí presentida en el texto", escribe Foffani. De ahí, prosigue, la presencia de adverbios de negación o de asentimiento al comienzo de muchas "voces", y cita algunas. ${ }^{6}$ Cabe añadir que hay en las Voces otra marca gramatical de este carácter dialógico, que es la conjunción y colocada al comienzo de muchas "voces", que plantea la existencia de un interlocutor ante el cual se completa un argumento expuesto con anterioridad. ${ }^{7}$ Así, tanto el adverbio de negación o de afirmación, como la conjunción $y$, delatan la entonación conversacional de las Voces. Porchia, que era un supresor casi maniático de palabras y de partículas inútiles, no eliminó este rasgo estilístico a lo largo de las sucesivas ediciones de las Voces, es decir, a lo largo de casi 25 años, lo que revela la importancia que le concedía y que se vincula con la conservación de un tono dialógico que para él debía de ser imprescindible para la creación de sus sentencias. En este sentido, la "música" de Porchia hay que buscarla no tanto en el tejido interno de sus frases, sino en la amalgama que une una "voz" con otra y que convierte su libro en una charla a media voz, dentro de la cual cobran sentido los sí, los no y los $y$ que parecen perfectamente omisibles en el interior de cada aforismo.

En su ensayo Antonio Porchia, el poeta del sobresalto, Alberto Luis Ponzo afirma que cada sentencia de Porchia es "una frase que pesa como un cuerpo cayendo con sus enigmas y desgarraduras". La norma del poeta consistiría en "aliviar la caída, poner en mitad del espacio una voz como una mano que contiene el golpe". ${ }^{8}$ En efecto, al leer las Voces, uno siente que esas máximas de plomo, en caída libre, han hallado un misterioso

6 "No, no entro. Porque si entro no hay nadie" (79); "Sí, me apartaré. Prefiero lamentarme de tu ausencia que de ti" (81); "Sí, están equivocados, porque no saben..." (30).

7 "Y si no puedo decirte nada sin lo que yo me digo..." (46); "Y si llegaras a hombre..." (60); "Y seguiré navegando por mares ajenos..." (95), etcétera.

${ }^{8}$ Alberto Luis Ponzo, Antonio Porchia, el poeta del sobresalto, 63. 
elemento amortiguador que las torna amigables. He tratado de mostrar que ese elemento amortiguador trabaja en el interior de cada aforismo, separando y descomponiendo los grumos y los automatismos lingüísticos, a través de un movimiento esclarecedor de todos los nexos en el cual juega un papel crucial la repetición, que es sin duda el rasgo más característico de las Voces. A través de la repetición Porchia encuentra el tipo de aforismo que necesitaba escribir, un aforismo cuyo gusto por lo paradójico lo acerca más a los proverbios que a los aforismos propiamente dichos. Él, que nunca se molestaba por nada, no podía soportar que definieran sus "voces" como aforismos, pues debía de sentir que a través de ese término sus frases se reducían a meras aserciones brillantes, que era lo que menos le interesaba escribir. La repetición, en cierto modo, fue su antídoto contra la brillantez. Como dijo Juarroz, vivió casi como si no viviera y escribió casi como si no escribiese. La repetición, que alcanza en él un alto grado de refinamiento, fue la manera que encontró para escribir como si no escribiese, puesto que la repetición introduce una suerte de vinculación estrecha entre las palabras que parece saltarse a aquel que las escribe, como si éste fuera apenas un detonador. La voz se adelgaza hasta volverse impersonal y la oralidad, sin dejar de ser tal, no se asimila por completo al habla. El resultado es un híbrido, como cuando se subtitula una película con el mismo idioma en la que está filmada, donde los diálogos y los subtítulos, aun siendo los mismos, no embonan por completo. En este desfase sutil entre lo oral y lo escrito, que he llamado más arriba de naturaleza correctora, hay que situar la verdad del estilo de Porchia, el cual, sin desmentir su matriz oral, se nos mete a los ojos como un nítido precipitado de escritura.

En boca de un hablante de otro idioma, como era Porchia, la repetición adquiere además un sentido suplementario, porque representa tal vez el recurso más natural para abrirse un nicho en el idioma extranjero. A través de la repetición, el titubeo 
lingüístico del extranjero encuentra un asidero que le otorga confianza y objetiva su voz en el justo grado que necesita para no exhibir su alma al desnudo, pues el extranjero que exhibe su alma al desnudo, exhibe su lengua materna. La repetición, como vimos, "hace texto", pero también "hace máscara", y texto y máscara hacen estilo. En el caso de un hablante extranjero la repetición viene a ser una herramienta ambigua, porque emula su torpeza verbal, elevándola a condición de poesía. Transforma su ineptitud en profundidad. El extranjero usa una misma palabra para significar cosas distintas porque no domina el idioma que habla; su pobreza de vocabulario lo fuerza a repetir; y la repetición, nacida de la carencia, se revela como un arma expresiva insospechada. Tomemos esta "voz": "Me es más fácil ver todas las cosas como una cosa sola, que ver una cosa como una cosa sola". Si la escuchamos con medio oído, haciendo abstracción del significado, parece el estribillo de alguien que tiene dificultad para expresarse. O esta otra: "Te ayudaré a venir si vienes y a no venir si no vienes", donde la repetición introduce un toque estrambótico y clownesco. ${ }^{9}$ Porque la repetición está cerca del balbuceo y del absurdo, y cuando escapa de las garras de estos últimos, consigue un gran vigor expresivo. Con una pequeña variación, con un mínimo derroche verbal, conservando el mobiliario en su sitio, expresa algo inédito y paradójico. Es como si a través de la repetición Porchia se hubiera propuesto, comprimiendo el discurso a todo lo que da, escribir una novela en cada aforismo, o sugerir la novela que cada aforismo oculta. Y escribió, en efecto, diminutas novelas como ésta: "El rosal: lo has visto con infinidad de rosas, lo has visto con una sola rosa, lo has visto sin ningu-

${ }^{9}$ En su brillante y ya citado artículo rememorativo, Alicia Dujovne Ortiz se ha referido a Porchia como un "meridional tocado por la Gracia y por la ridiculez, verdadero y teatral, cierto como un santo y, como un santo, absurdo, fuera del tiempo [...] la verdad de Porchia está acreditada precisamente por esa continua oscilación al borde de la perogrullada, por ese riesgo de lo ridículo que acompaña cada 'voz', cada acción de su vida". 
na rosa. Y no lo has visto nunca con una rosa de más ni con una rosa de menos. Es que has visto el rosal", donde parece retratar involuntariamente su propia escritura, plagada de repeticiones, concentrada y monótona, que siempre da las mismas flores, aunque esas flores sean rosas; creaciones que el autor ha recogido, no inventado; que ha compuesto más que escrito, del mismo modo que se componen las flores de un jardín. Pero hay aquí, también, una reflexión sobre la mirada. ¿Dónde poner el ojo para estar vivos, para mirar como humanos, para comprender de verdad? ¿Cómo admirar el rosal en su perfección, que no es menos perfección cuando carece de rosas? Creo que Porchia habría contestado: no viéndolo a él, sino deduciéndolo del jardín y de la rosa, o sea, de aquello que lo contiene y de aquello que le da sentido como rosal; ahí, en mitad del espacio, inferido más que visto, en equilibrio entre la plenitud de cada creación y lo absurdo de todo lo creado, está lo que vemos de verdad. Así, cuando dice en otra parte: "Mi sed agradece un vaso de agua, no un mar de agua", vuelve a plantear la cuestión de cómo situarse ante el mundo. El vaso de agua calma mi sed, pero la calma porque sé que proviene de un mar de agua; de no ser así, ningún vaso de agua sería suficiente para mi sed de ahora; de modo que a mi sed no la calma ni el vaso de ahora ni el mar de después, sino el punto en que se encuentran el agua de uno y el agua del otro, pues toda sed no es sólo sed de agua, sino de realidad. Que este punto de encuentro sea nebuloso, sólo corrobora lo difícil que es vivir, y, sin embargo, sólo en ese punto incierto, sólo en esta nebulosa lejana, las cosas existen. Por eso, Porchia dice: "Cuando no ando en las nubes, ando como perdido", pues andar en las nubes, lejos de lo obvio, es la condición para ver de verdad, y es lo propio del poeta. Situadas en el último límite del sentido, en la máxima altura desde la cual es todavía posible producir una sombra, las nubes son la imagen misma de lo paradójico, y la poesía, esa forma acentuada de la lucidez, ama expresarse por paradojas. Lo que hace la poesía es 
crear sombra y altura, imitando las nubes. Se extralimita como ellas. En cierto modo, las nubes representan un exceso de salud. Evanescentes e inaprensibles, son las grandes hacedoras de espacio, las que nos sitúan en el mundo, que es también la tarea de la poesía, otro exceso de salud. El libro de Porchia, en lugar de Voces, bien pudo haberse llamado Nubes, con lo cual habría sido más evidente ese rasgo de "contención del golpe" al que se refiere Alberto Luis Ponzo, pues ¿qué son las nubes sino aquello que alivia la caída de nuestra mirada, poniendo en mitad del espacio vacío una mano salvadora?

Puede decirse, pues, que toda la obra de Porchia es un poner atención a los límites que, aun evanescentes, nos protegen del sinsentido. Como buen jardinero, sabe que un jardín siempre está en duda: si se extralimita, el exterior lo borra; si se queda estático, se envilece. El jardín debe defender su individualidad, pero sin cerrarse. "Si quieres que las flores de tu jardín no mueran, abre tu jardín", reza, justamente, una de sus "voces". Abrir, enlazar, profundizar: las tareas de un buen jardinero no son muy diferentes de las de un buen aforista o de un buen poeta. Hay que abrir la frase para que el sentido no se pudra, y abrir significa poner en relación y formar contigüidades. La jardinería, como la escritura, es un arte de estrechar vínculos. Porchia quisiera hallar la medida de la vinculación perfecta, y por eso se lamenta, casi la única vez que se lamenta de algo: “¡Ah, si pudiera dejar todo como está, sin mover ni una estrella, ni una nube. ¡Ah, si pudiera!”. Es el reclamo, en el fondo, de todo jardinero, que tiende a ver su jardín como un espejo del universo y se pregunta si no será posible sujetar, al igual que sus flores, las nubes y las estrellas; más aún: si no es eso, justamente, lo que ha intentado hacer a través de su jardín, y la conciencia de no poder lograrlo se revierte sobre el jardín mismo, que se muestra tan indomable y profundo como el universo y perpetuamente inacabado como una frase. La escritura, entonces, que parecía el jardín supremo, capaz de dar todas las respuestas a nuestras 
inquietudes, se muestra más evanescente que las mismas nubes y menos confiable que la flor más efímera: "Lo que dicen las palabras no dura. Duran las palabras. Porque las palabras son siempre las mismas y lo que dicen no es nunca lo mismo". Recordemos, una vez más, el bilingüismo de Porchia. Adaptarse a otra lengua nos enfrenta a la dureza y extrañeza del lenguaje, junto con la sospecha de que las palabras, en lugar de acercarnos, nos dejan fuera de lo esencial. Quizá sólo alguien que no llegó nunca a reconocer totalmente como propio el idioma en que se expresaba, pudo escribir: "He llegado a un paso de todo. Y aquí me quedo, lejos de todo, un paso”. ¡Llegar a un solo paso de la meta, haciendo de un solo paso la mayor distancia imaginable! En cierto modo Porchia hizo de ese paso faltante, de esa inminencia perpetua, de esa ridiculez metafísica, la razón de su vida y el núcleo de su poética. Fue el hombre que siempre estuvo un paso atrás de donde se le permitía estar, no por timidez o por pusilanimidad, sino porque creía que era la única manera humana de convivir con los otros. Una "voz" como ésta lo pinta de cuerpo entero: "Donde hay una pequeña lámpara encendida, no enciendo la mía”. Es una de las frases más delicadamente humanas que se han escrito y retrata la frugalidad de Porchia, su quietismo, su don de renuncia, su saber conformarse con lo que la vida le dio y, en especial, su capacidad de hacer lugar, quizá su don más alto. Es probable que sus vicisitudes de inmigrante lo educaron a esto, pues quien emigra busca su lugar en la nueva realidad que lo rodea y procura hacerlo del modo más natural que puede, para ser tomado justamente como un natural y no como un extraño; así, todo lo que ocupa un lugar ha tomado el lugar que otro le ha cedido, y los advenedizos y los carentes de lugar lo saben mejor que nadie. Guiado por ese sentimiento de transitoriedad y migración que nunca lo abandonó, Porchia pudo escribir: "Las certidumbres sólo se alcanzan con los pies", y pudo haber escrito, al calor de esta afirmación, que la escritura que adolece de pies no es escritura; que la escritura 
que es puras manos, es falsa, porque las manos escriben lo que los pies les dictan. Así, al menos, escribió él, supliendo con los pies, con el peso de lo vivido, su insuficiente manipulación de un idioma que aprendió tarde. Escribió doblemente de prestado: en un idioma que nunca fue del todo suyo y en un género, el aforismo, en el cual se abdica de la propia voz para que su brevedad perdure. Así, cuando afirma: "El sol ilumina la noche, no la convierte en luz", no hace más que elevar a un plan metafísico esta condición de préstamo o de simulacro, al recordarnos que lo que llamamos día es apenas una noche iluminada, o sea, una dádiva momentánea. Carentes de luz propia y de atributos fijos, de cualidades esenciales y de un rostro duradero, somos tan sólo el camino sembrado de nuestras caídas, después de cada una de las cuales, tirados en el suelo, nos decimos que todo está bien y que no podría estar mejor, como esos clowns de circo del que Antonio Porchia fue un émulo involuntario, capaz como fue de transformarse en cada una de sus máscaras, de darse por entero en cada uno de sus rostros y de agotarse en cada una de sus "voces". 


\section{REFERENCIAS}

Cerrato, Laura, "Prefacio" a Antonio Porchia, en Voces abandonadas, Valencia, Pre-Textos, 1992.

Doвry, Edgardo, "En el espejo de Alejandra Pizarnik", en Orfeo en el quiosco de los diarios, Buenos Aires, Adriana Hidalgo, 2007.

Dujovne Ortiz, Alicia, "Antonio Porchia: 'Voces' del silencio", nota aparecida en Clarín, Buenos Aires, 8 de noviembre de 1973.

Foffani, Enrique, "Las Voces de Porchia entre lo breve y lo fragmentario" (inédito).

Ponzo, Alberto Luis, Antonio Porchia, el poeta del sobresalto, Buenos Aires, Epsilon, 1979.

PorchiA, Antonio, Voces reunidas, Daniel González Dueñas y Alejandro Toledo con la colaboración de Ángel Ros (ed., pról., tabla de variantes, anexo y epílogo), Valencia, Pre-Textos, 2006. 
